
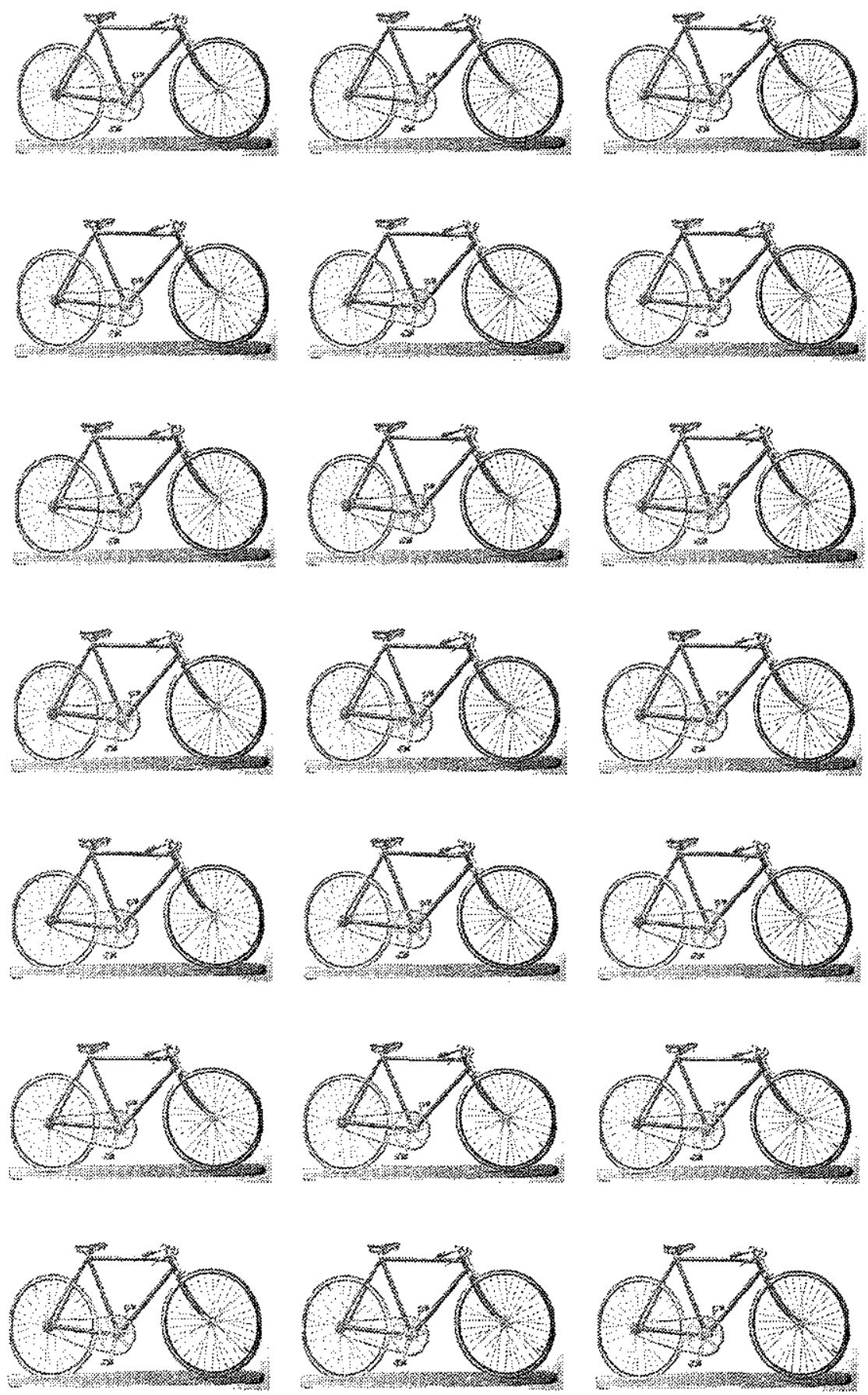


\title{
¿POR QUÉ PIONEERS OF MODERN DESIGN DE NIKOLAUS PEVSNER ES LO QUE ES?*
}

\author{
Manuel Corrada \\ Universidad de Chile \\ Pontificia Universidad Católica de Chile
}

\begin{abstract}
EN 1936 NIKOLAUS PEVSNER PUBLICO PIONEERS OF MODERN DESIGN. EL LIBRO ABARCA LOS AÑOS 1880-1914, DE MORRIS A GROPIUS. EN ESOS DÍAS, GENERAL MOTORS ESTABA ENVIANDO

ENCUESTAS A MILES DE DUEÑOS DE AUTOMÓVILES PREGUNTÁNDOLES QUE ESTILOS LES GUSTABAN, POR QUÉ, QUÉ ESPERABAN DE UN AUTOMÓVIL NUEVO; EN RESUMEN, HACIENDO INVESTIGACION DE LOS CLIENTES. NO PARECE CAUSALIDAD QUE TAMBIÉN EN LA MISMA ÉPOCA Y POR PRIMERA VEZ LOS DISEÑADORES INDUSTRIALES, ADEMÁS DE SUS PREOCUPACIONES ESTÉTICAS, COMENZARON A SER CONSULTADOS ACERCA DE LO QUE “QUERÍA” EL PÚBLICO. SIN EMBARGO, EL LIBRO DE PEVSNER ESTÁ CIEGO A ESE TİPO DE CONSIDERACIONES, Y SU UNIVERSO DE OBJETOS MATERIALES SE REDUCE LAS ARTES DECORATIVAS $Y$ A BIENES DOMÉSTICOS PREINDUSTRIALES.
\end{abstract}

El título de este artículo alude a uno de los libros sobre diseño más leídos, publicado en londres en r936, Pioneers of the Modern Movement, y años después Pioneers of Modern Design en la edición MoMA de 1949. Influyente sobre todo el espectro del campo del diseño, a menudo se lo refiere como una genealogía del diseño, como un canon de lo que el diseño debería ser, como el camino que debe seguir el diseño y como el que define el papel social que los diseñadores deberían asumir. Pero, por cierto, su poder para predecir no calza ahora con esa descripción. El tiempo cuenta otra historia, casi la contraria. Vivimos en un planeta lleno de objetos diseñados mucho más amplio que el de los meramente domésticos. Los cambios sociales son fruto de la política y no del diseño como pronosticaba el autor. El motor tras los productos industriales apunta al beneficio económico y el gusto no emana por decreto

\footnotetext{
* Trabajo presentado en 3rd Internotionol Conference on Design History and Design Studies, 9-iz Julio 2002, Estambul, Turquía. Texto original en ingles traducido al español por el autor.
} 




sino desde estructuras sociales y culturales profundas.

Este artículo trata de ponderar modestamente el alcance y los supuestos de Pioneers. Escrito por Nikolaus Pevsner (1902-1983), historiador del arte y la arquitectura, el libro abarca los años r880-זgr4, de Morris a Gropius. Su fin principal fue describir el nacimiento del Movimiento Moderno en arquitectura, un asunto que incluso hoy días provoca polémicas.

Para Pevsner el diseño es la actividad que hacen quienes dan forma a los objetos de uso cotidiano. Aunque, en realidad, se toca meramente como la actividad que añade evidencia para fundamentar la narrativa hasta cierto punto teleológica del libro. El diseño es diferente de la arquitectura, los deslizamientos en diseño refuerzan las variaciones en arquitectura. Sin embargo, el diseño no tiene participación en las causas desde las cuales emerge el Movimiento Moderno. El diseño entra en el relato de Pevsner simplemente como una zona para lanzar opiniones morales y políticas sobre el arte, la política y la sociedad, ya que los objetos de producción masiva poseen un público mucho más extenso que los edificios.

\section{CAPITALISMO}

Los economistas decimonónicos, Ricardo, Marshall, Marx, se concentraron en el conceptode valor. No obstante, la pregunta acerca de las relaciones entre trabajo y valor separaban sus posturas. La pertinencia de tal pregunta radicaba en la importancia del intercambio de bienes como consecuencia de la industrialización. Dejando de lado esas discusiones acerca del hilo económico entre valor y precio, todos esos economistas consideraron la incidencia del trabajo para determinar el valor.

¿Está el trabajo de los diseñadores inmerso en los productos industriales? $\mathrm{Si}$, resulta evidente. Remontándonos a un distingo de Adam Smith, quien definió el valor productivo en términos de mercancías físicas, no de servicios en la época de Smith, vemos cómo el trabajo de los diseñadores importa de verdad.

Miren ustedes los objetos diseñados que aparecen en las páginas de Pioneers. El inventario es el siguiente: alfombras (3), chales (I), papel mural (2), chintz y telas 
estampadas (2), platería (4), plaqué ( $\mathrm{I}$ ), ilustraciones ( $\mathrm{r}$ ), sillas (3), floreros de cristal (2), interiores (ro), bancos ( $x$ ), armarios ( $\mathrm{I}$ ), lámparas callejeras ( $\mathrm{I}$ ). De inmediato surge una pregunta: ¿qué tienen en común todos esos objetos?

El denominador común de todos esos objetos es que pueden fabricarse sin la intermediación de un proceso industrial, sin máquinas, por artesanos sólo con sus herramientas y usando técnicas tradicionales. Ninguno de esos objetos necesita industria pesada, producción en cadena y división del trabajo. Ninguno es el resultado de la innovación tecnológica o de la aplicación del conocimiento científico en la industria. Con la única excepción de la lámpara urbana, esos objetos forman parte de la vida burguesa preindustrial.

El teléfono, el gramófono, el transporte público, las llantas neumáticas, las bicicletas, las máquinas de escribir, la seda artificial, las novedades baratas de circulación masiva y la bakelita fueron cosas alejadas del interés de Pevsner; en fin, los productos característicos de los procesos industriales quedan excluidos de los pocos que el considera. Mas aun así, Pevsner nota que gracias a la industrialización la cantidad de bienes aumenta, "la demanda fue creciendo año tras año". Sin embargo, esta demanda creciente fue calificada con un sentido de moralina social, "pera era la demanda de una población sin educación, viviendo vidas de esclavos en la miseria y penuria".

En estas líneas podemos leer tres puntos. Primero, la idea capitalista que en el intercambio de bienes presenta la producción como respuesta a la demanda. Segundo, el hecho evidente de que con la industrialización aumentó la producción de bienes. El tercer punto, el que se refiere a la población, en realidad no pertenece al ámbito económico sino que es un comentario ideológico. Incluso podemos oír que sus denuncias sociales a veces adquieren el tono de romanticismo nostálgico, "la indisoluble unidad del arte de una época con su sistema social. Solamente William Morris vio esto".

Pero la unidad del arte de Morris con sistemas sociales posee matices: "Morris fue incapaz de apreciar la posibilidades positivas de los materiales nuevos, porque estaba demasiado preocupado con las consecuencias 
negativas de la Revolución Industrial. Solamente vio lo que se había destruido: la artesanía y el trabajo placentero". Este comentario contiene una paradoja. Por un lado, la crítica de Pevsner a la Revolución Industrial $E_{L}$ es la mayor parte de las veces negativa. Por otro, las

PROPÓSITOO

ERA DENUNCIAR

LOS OBJETOS

PASADOS DE

MODA limitaciones que encuentra en Morris son precisamente las suyas propias. Morris aparece como una figura que evoca un tiempo perdido e idílico, pero no obstante gran parte de su desprecio del aspecto visual, o en las palabras de Pevsner "patrimonio visual", o "razones visuales", sólo más tarde adquirió su relevancia debida para el diseño.

Las líneas precisas de las estructuras de hierro, la geometría de las obras de ingeniería, como los puentes, son las líneas que como malla de composición, junto con la exaltación retórica de los maravillosos propósitos de Morris y del Arts and Crafts Movement, forman el catecismo del Movimiento Moderno. Pevsner estaba escribiendo su hagiografía épica.

\section{ARTE}

Para captar la tendencia estética de Pioneers, debemos ahora fijarnos en sus imágenes y lo escrito sobre ellas. Con este propósito, de algo nos servirán las alcuzas, aunque apenas sea para hablar de los pensamientos inmersos en ellas. Se trata de útiles domésticos que en el siglo XIX formaban parte de la ceremonia cotidiana de comer. En el libro aparecen dos juegos de plata, de 1877 y 1878 diseñados por Christopher Dresser, "un diseñador profesional para la producción industrial". Sus cualidades son "simplicidad y osadía creativa", "en todos los detalles reducidas a lo fundamental, como eran los primeros diseños de Morris", y en seguida mediante una comparación negativa las contrasta con platería de la Exposición de $185^{\text {I a la que }}$ Pevsner describe como "indignante".

La estrategia visual de confrontar imágenes para desarrollar un programa cuyo fin es mostrar superioridad fue bastante usada por el Modernismo. El propósito era denunciar los objetos pasados de moda como poco higiénicos, poco confortables, frente a los cuales los nuevos objetos del diseño con sus líneas inmaculadas resultan redentores. Para ver una caricatura de esta táctica sólo 
basta hojear L'Esprit Nouveau, una revista de propaganda del modernismo que apareció entre 1920 y 1925. En ella encontramos fotografías de cosas antiguas con precios muy altos junto a las cuales están cuadros modernos y muebles, relativamente baratos en comparación con los objetos antiguos. Así, por polaridad, la triquiñuela afirma la superioridad del estilo moderno.

Veamos el otro juego de alcuzas. Fue diseñado por C. F. Annesley Voysey, un representante en diseño "de esta nueva joie de vivre". También aquí Pevsner encuentra "simplicidad refrescante", y que el "encanto reside únicamente en la limpieza y gracia de sus figuras". La simplicidad incluso trasciende su pertinencia a las cosas particulares. Las lámparas callejeras de Peter Behrens "muestran las misma pureza de forma, la misma sobriedad al limitar el diseño a formas geométricas simples, y la misma belleza de proporción que nos deleita en los edificios de Behrens". ¿Puede compararse una lámpara con un edificio? Son artefactos tan lejanos que intentar juntarlos parece a todas luces arbitrario. En realidad, lo es. Porque lo que importa "para el Movimiento Moderno que viene fue la expresión de este espíritu nuevo". Espíritu nuevo diferente del antiguo debido a su simplicidad formal, entre otros muchos motivos.

La simplicidad no es un mero adjetivo. Encierra una virtud, pero una virtud definida negativamente como antídoto contra la ornamentación excesiva, aversión a la afectación. Al final del siglo XVIII, algunas de las reflexiones sobre arte de Sir Joshua Reynolds se ocupaban de la simplicidad. El observó su carácter negativo: "podemos explicar mejor qué es correcto, mostrando que está equivocado; $y$, por cierto, en este caso parece absolutamente necesario: la simplicidad, siendo solo una virtud negativa, no puede describirse o definirse". Reynolds sugiere que debido al carácter negativo de la simplicidad, tan negativo como el "espíritu nuevo" de Pevsner, lo que se intenta describir debe hacerse en referencia con una situación existente.

Una manera parecida de mirar la simplicidad más de cerca se refiere a la afirmación laudatoria de Pevsner acerca de ella. Es considerar la simplicidad como una metáfora visual, una de las metáforas en el discurso visual. Muchas

\section{L.A}

SIMPLICIDAD, SIENDO SÓLO UNA VIRTUD NEGATIVA, NO PUEDE DESCRIBIRSE o DEFINIRSE 
veces las descripciones recurren al lenguaje metafórico para poner en evidencia algunas características que no se aplican propiamente. La tendencia en las alfombras a los "colores fuertes" solo por vía metafórica nos permite comprender que un término relacionado con la potencia y la resistencia pueda aplicarse a un fenómeno óptico. Ernst Gombrich ha estudiado cuidadosamente el papel que adquieren esta clase de metáforas en la misma época que a la que se refiere Pevsner. Según dice, "para hacer unas tijeras dignas de elogio, el diseñador victoriano les dio forma con el molde de un trazado gótico, para que compartieran el aura de valor que rodeaba las reliquias de la "Edad de la Fe".

Para los Victorianos el ornamento fue la metáfora para el Arte. La reacción a esa estética se tradujo en la emergencia de metáforas nuevas. El deslizamiento en las metáforas visuales, ilustrado como deslizamiento desde un interior victoriano al salón de té Cranston de Mackintosh, lámina 90 en Pioneers, puede verse en varios detalles. Los muebles llenos de alusiones vegetales cambian por la higiene del cromo. Pero Gombrich elabora las metáforas visuales un paso adelante, presentándolas como un signo de un deslizamiento de valor. La negación de la ornamentación pomposa y en su lugar la virtud de la "simplicidad" significa que los objetos endosados con simplicidad demuestran valores más altos y llevan cualidad moral superior, "a través de tal negación, restricción, o renuncia, ese arte crea metáforas nuevas de "valor más elevado'". Para Pevsner, el valor superior

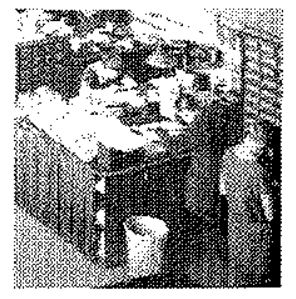
del arte moderno, por ejemplo el de Cezanne, el mismo valor que también corresponde a los objetos de diseño, se contrasta con las tijeras victorianas que comparten el sino del valor del arte medieval.

Encontrar valor fuera del campo propio queda mejor ejemplificado en un episodio de la Recherche de Marcel Proust. El joven narrador recuerda a su abuela, quien vivió a finales del siglo XIX, y cómo a ella le gustaban los bienes y objetos. Por sobre cualquier otra consideración, por decir práctica, a ella le gustaba todo lo que tenía valor artístico o intelectual. A veces, el valor estaba solo en su calidad antigua, como si el tiempo hubiera borrado cualquier utilidad páctica y dejado sólo su carácter 
histórico, un valor en sí mismo. También temía a los medios mecánicos de reproducción, principalmente a la fotografía. Era mucho más comercial que artística.

Y la idea de transportar el valor artístico de un lugar, un edificio, a otro, una fotografía, le parecía que dejaba abierta la posibilidad que algo de ese valor se perdiera en el camino. Por ese motivo, en vez de una fotografía de la catedral de Chartres o del Vesubio, prefería la fotografía de esos lugares pintados por un gran artista, la Catedral de Chartres por Corot y el Vesubio por Turner. Así se garantizaba la fidelidad en la transmisión de valor. Sin embargo, el narrador reconoce que este salto doble, primero de la realidad a los cuadros y luego de éstos a las fotografías, puede llevar a interpretaciones equivocadas. Una simple fotografía de Venecia es más exacta que un dibujo de Tiziano de Venecia.

En cierta medida, Pevsner es como la abuela del narrador proustiano. El aire fresco que terminará en el Movimiento Moderno viene de afuera, de la pintura. Las cualidades que hay que transportar de la pintura están en la misma esfera que la simplicidad. "superficies lisa y $\sin$ quiebres", "contorno dibujado rítmicamente", "colores fuertes y figures primitivas", "esquemas de composición duros". Estas son algunas de las frases que esconden metáforas del arte, junto con otros enunciados cuyo significado se obtiene por negación, "no cercanía a la realidad sino expresividad de esquemas es lo que importa", y con un propósito de valor "en lugar del arte por el arte, puede ser algo arte que sirva a algo más elevado que el arte".

No obstante, lo que no resulta obvio es cómo transportar esas metáforas al panorama extenso de los objetos industriales diseñados. Pero la narrativa de Pevsner tiene una cláusula de escape. Excluye cualquier cosa que no cuadra con sus requisitos estéticos y que muchas veces pertenece al infierno de las atrocidades de Pevsner.

Las causas detrás de tan abominable estado de los objetos diseñados no pueden dejarse de lado. Por una parte, resulta del efecto siniestro de la industrialización que reemplazó las manos delicadas de los artesanos por la frialdad de la industrialización. Por otra, los

\section{PeVsner ES COMO LA ABUELA DEL NARRADOR PROUSTIANO}


productores sin educación sumados a los usuarios nuevos no tienen sensibilidad crítica, mejor dicho, ignoran las virtudes y cualidades del arte. Esta postura nos recuerda una traición análoga, usando un método mecánico de reproducción con las mismas líneas argumentativas. Si la industrialización permitió reproducciones múltiples de objetos únicos que tradicionalmente eran hechos por artesanos, la fotografía hizo lo mismo con las imágenes que por siglos había sido el privilegio de los talleres de pintura.

Todos sabemos que en el siglo XIX el invento de la

[PEVSNer] NO CONSIDERA

EL CONSUMO

EN EL PERÍODO QUE ESTUDIA fotografía pronto encendió muchas polémicas acerca de si debía considerársela arte y acerca de la verdad de las imágenes fotográficas. Sin embargo, la pregunta por la categoría artística de la fotografía es un círculo vicioso, porque depende sobre qué consideramos arte y qué no; $y$, especialmente si de antemano definimos y caracterizamos arte de cierta manera entonces así ya está decido si la fotografía pertenece o no al arte.

Walter Benjamin observó los esfuerzos de los primeros fotógrafos por parecer artísticos, por ejemplo, al presentar ambientes artísticos para transferirlos a la nueva técnica de reproducción. Columnas y cortinas aparecen en lienzos hermosos de la alta pintura. Por lo tanto, el espacio que se representa en la fotografía debe por consiguiente tener columnas de mármol y cortinas de terciopelo, incluso, como observa irónicamente Benjamín, colurnnas sobre una alfombra. Mas si estas argucias dudosas provienen del esfuerzo por considerar la fotografía como arte, Benjamin pregunta, "¿qué clase de arte producen los nuevos métodos de producción?"

En otras palabras, bajo la consideración acerca del grado artístico de la fotografía subyace el problema conectado con el valor artístico. En este contexto, Victor Burgin observó que la fotografía tiene que cargar con la herencia de la historia del arte, y algo parecido podemos notar en la introducción de las áreas del arte y la arquitectura en el diseño como lo hace Pevsner.

Porque este mismo tipo de herencia de categorías artísticas se aplica al diseño según lo concibe Pevsner. Si para la fotografía esas categorías eran una manera de protegerla contra el poder institucional del arte, para Pevsner la narrativa sobre diseño significa dejar de lado 
las coordenadas económicas del diseño industrial. Claro, necesitaba hacerlo a fin de producir una genealogía consistente para el Movimiento Moderno en arquitectura. La estrategia ideológica fue cubrir todo con valores artísticos.

\section{DISEÑO}

Resulta perfectamente obvio que los objetos del diseño los consumen muchas personas. La economía dicta que la oferta de bienes está regulada por la demanda, cualesquiera que sean los matices morales o ideológicos que consideremos. Así, la producción industrial de objetos del diseño forma parte del sistema capitalista. En la historia económica, el periodo en el que se concentra Pevsner corresponde con la emergencia del capitalismo corporativo en los Estados Unidos y la "cartelización" en Europa. Fue una época de una creciente oferta de bienes igual que lo fueron los años que describe Pevsner en Pioneers. Ese mundo de bienes cotidianos cuyo consumo crecía significó que algunas personas prefirieran algunos objetos sobre otros, que las personas eligieran en el universo de los objetos del diseño.

Pero Pevsner no vio nada de eso. No considera el consumo en el período que estudia ni en la narración que hace de él. Pese a que conocía bien las coordenadas económicas, prefirió quedarse mudo sobre ellas. Después de enumerar el aumento de la población, las exportaciones de algodón, la producción de hierro en Inglaterra durante la primera mitad del siglo XIX, escribe:

\footnotetext{
In the midst of this breathless race, no time was left to refine all those innumerable innovations which swamped producer and consumer. With the extinction of the medieval crafrsman, the shape and appearance of all products were left to the uneducated manufacturer. Designers of some standing had not penetrated into industry, artists kept aloof, and the workman had no say in artistic matters.
}

Luego observa que su causa se debe, por lo menos en parte, a la libertad del liberalismo 
consumer had no tradition, no education, and no leisure, and was, like the producer, a victim of this vicious circle.

Para ÉL, UN UNIVERSO ENTERO DE PRODUCTOS $Y$ DE SUS DISEÑADORES FUERON INVISIBLES
En estas líneas podemos oír que la situación sería mejor si los bienes fueran producidos por designers of some standing y consumidos por personas educadas. Un buen propósito pero alejado de la realidad, tanto hoy como en los tiempos de Pevsner.

En los años 1840 y 1850 la expansión del diseño en Inglaterra incluyó el papel mural, alfombras, cerámica y chintz, y las personas que producían todos esos bienes tenían que habilitarse en las Escuelas de Diseño. En la primera mitad del siglo XIX William Dyce y Benjamin Robert Haydon argumentaban acerca de si los diseñadores eran artistas liberales o trabajadores manuales superiores. Mas aún, sabemos que en el siglo XIX existían otras formas de empresas de capital que eran alternativas al sistema perverso de las fábricas, algunas de las cuales incluso crearon habilidades nuevas. La ceguera de Pevsner excluyó todo esto y cualquier cosa que no cuadrara con sus asuntos morales y prejuicios artísticos.

En efecto, excluyó uno de los productos más populares en el cambio de siglo: los automóviles. Miremos unos datos. En Estados Unidos, la proporción de salida de artefactos eléctricos domésticos creció de $0 \%$ en r 1879 -1889 a $0.73 \%$ en r929-r939. Las radios subieron de $0 \%$ a 0.80 $\%$. Los vehículos motorizados de o a $6.18 \%$, los accesorios para vehículos motorizados de o a $.4 \mathrm{x} \%$, mientras que los vehículos tirados por caballos cayeron de $1.05 \%$ a $\%$.

Este producto nuevo, el automóvil, fue para Reyner Banham, otro apologista del Movimiento Moderno, "la máquina simbólica de la Primera Epoca de la Máquina". Sin embargo, para Pevsner los automóviles no existen porque tampoco existe el consumo, por lo menos según se lo considera usualmente. Рara él, un universo entero de productos y de sus diseñadores fueron invisibles, igual que lo fue el hecho que esos productos fueron consumidos por personas de carne y hueso y no por entidades genéricas como las que consideró en su esquema.

Ahora bien, sabemos que en esos mismo días, General Motors estaba enviando encuestas a miles de dueños de automóviles preguntándoles que estilos les gustaban, 
por qué, qué esperaban de un nuevo automóvil, en otras palabras, haciendo investigación de los consumidores. También en ese tiempo y por primera vez, los diseñadores industriales además de sus preocupaciones estéticas comenzaron a ser consultados acerca de qué "quería" el público y este tipo de información fue empleada extensivamente en la muestra de Dupont en la Texas Centernial Exposition de 1936.

Echemos un vistazo a las encuestas de General Motors. Son folletos amables dirigidos a las consumidores con preguntas muy simples, por ejemplo, iestilo deseado del automóvil siguiente?, ¿coupe?, ¿convertible?, ¿sedan?, o si preferirían un frente plano o curvo. Esta información revierte en diseño porque el círculo es cerrado. En este lazo, el lugar y papel de los diseñadores es bastante parecido al que plantean aproximaciones semióticas recientes al diseño en el ciclo productivo, por ejemplo la de Klaus Krippendorff donde el lazo diseño-manufacturadistribución- consumo incluye al consumidor, es decir, los problemas de usuario observados durante la investigación de los consumidores se resolverán en una nueva vuelta del ciclo.

La cabeza detrás de todas esas estrategias era Henry G. "Buck" Weaver, director de Customer Research Staff para $G M$ desde I933. Su creencia en escuchar a las personas, con fines comerciales, por cierto, fue mucho más lejos de lo que hoy día llamamos trenders o trend forecaster. Las encuestas de 1932 revelaron que a las personas las atraía el diseño aerodinámico, pero Weaver notó también que visualmente los automóviles de juguete eran "del diseño ultramoderno de la línea de producción". Las tendencias de la cadena productiva implicaban que $G M$ debía mostrar que su poder de cambio continuo resultaba en el diseño de nuevos modelos de automóviles. Aquí, producción en cadena es una práctica y estilo real mientras que para Pevsner fue una especie de inspiración.

Por supuesto, podemos objetar las comparaciones entre Weaver y Pevsner pese a que ambos consideraron productos del diseño industrial durante los mismos años, pues sus fines eran diferentes. Uno era un hombre de negocios y el otro un historiador del arte. Ciertamente, es verdad. Pero lo que para Weaver acaba en la materialización de

\section{UNO ERA \\ UN HOMBRE DE NEGOCIOS Y EL OTRO UN HISTORIADOR DEL ARTE}


un estilo para Pevsner significa la imposibilidad de ver al público como consumidor de objetos y bienes. Una cita de una de las encuestas de GM subraya este punto

La cita es de Baltasar Gracián, un cura espanol del Barroco que fue un prestigioso escritor moralista, pero cuyos escritos jamás estuvieron en la zona popular a la cual iban dirigidas las encuestas. La función de la cita era otra. Impresa en una página del folleto, junto con algunas preguntas generales de identificación del cliente, su mensaje subyacente le decía a cada cliente individual "ustedes son importantes para nosotros". Reproduzcamos la cita: "es más importante conocer las características y propiedades de las personas que las de los vegetales y minerales". En fin, quisiéramos saber sus características y propiedades, ¿para que?, ¿qué revelan?

Revelan los gustos de los consumidores. El gusto nunca es genérico y anónimo sino específico e individual y anclado en la sociedad. En la actitud de Pevsner, por un lados encontramos a las personas poco cultivadas, pero, sin embargo, en el lado positivo no encontramos nada. Esta fue una concepción falsa típicamente modernista que incluso Pevsner reprodujo en su obra teórica acerca del modernismo.

Alguna vez Theodor Adorno habló de "prototipos" como aquellos en la mente de los profetas del Movimiento Moderno. Clive Dilnot los llamó el "otro abstracto" como opuestos al "otro concreto", y mostró por qué el modernismo en su peor momento "nos entrega una concepción del sujeto cuyo embodiedness fue inmediatamente racionalizado y reducido, digamos, a un conjunto de criterios ergonómicos". Pero esos prototipos $\mathrm{y}$ otros abstractos no pueden responder la pregunta "¿por qué quiero lo que quiero?" No, porque son meras abstracciones.

Esta pregunta, sin embargo, esta detrás de cualquier teoría del consumo, ya sea desde un punto de vista antropológico o económico. En relación con eso, encontramos las moralinas de Pevsner referentes al bajo nivel tanto de fabricantes como de consumidores lo que es la causa de bienes mal diseñados. Mas según enseñan los estudios etnográficos, los bienes juegan un papel en la vida social, desde los más ricos hasta los más 
pobres, independientemente del estatus jerárquico de instrucción de sus miembros. Los bienes son "marcadores" de inclusión en las comunidades sociales y un medio de interacción social. Algunas atrocidades, como las calificó Pevsner, resultan del diseño de productos y pueden vivir en el espacio del consumo. Otros bienes, como los automóviles, viven en el mismo espacio y son de lejos más exigentes de diseño que cualquiera de los que muestra el libro de Pevsner. Sin embargo, ellos salen del trabajo de otra gente, del de los consultores de diseño.

Ciertamente ha habido episodios históricos en los que sentimos una batalla de valores causada por un deslizamiento de un trabajo a otro, por decir algunos, de la pintura a la fotografía o de la arquitectura al diseño. Walter Benjamin, por ejemplo, observó que la demanda artística sobre la fotografía coincidió con el hecho que los primeros fotógrafos fueron pintores que no siguieron el camino de la vanguardia. En tales asuntos amorosos, como éste o como el de la arquitectura con el diseño, el poder de la actividad envuelta con más estatus en la jerarquía social se ejerce sobre la que tiene menos poder transfiriéndole a ésta un conjunto de valores, criterios y reglas. Como tal, el diseño fue colocado en una posición sumisa de la arquitectura. Pero parece adecuado señalar que también la arquitectura había sufrido una dependencia similar. Algunos orfebres del Renacimiento italiano eran muy apreciados por su talento de diseño y su pericia técnica. Eran tan hábiles haciendo modelos y dibujos que fueron llamados a dar ideas de arquitectura para edificios, como en los casos de Brunelleschi y Michelozzo.

En realidad, poner en paralelo asuntos amorosos entre actividades del Renacimiento con las del Modernismo sirve para relativizar el papel de los arquitectos en el diseño y, al mismo tiempo, para decir que las actividades y discusiones interdisciplinarias cuando se hacen pertinentemente pueden enriquecer el trabajo. Si para los ojos de Pevsner los diseñadores deben guardar la esencia del arte y no contaminarse con el capitalismo, el sistema económico detrás de la industrialización, los consultores en diseño juegan casi el papel inverso. Bastante se ha dicho de que la mezcla de los diseñadores con los ejecutivos de empresas en los años i930 llevó a los

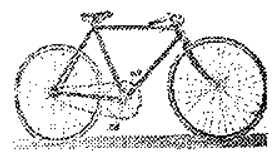




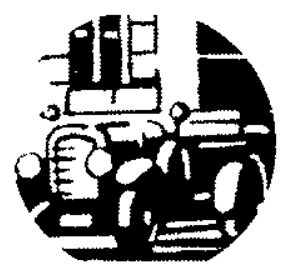

diseñadores a adaptarse estéticamente a los imperativos comerciales, y que de esa manera el modernismo fue apropiado por las grandes empresas estadounidenses. No obstante, hay un papel de la mayor importancia jugado por esos diseñadores: "a menudo los diseñadores promovieron una orientación hacia los gustos culturales de las masas tanto como los hicieron en la adopción de los estándares estéticos del arte elevado". Así, el trabajo de esos diseñadores estableció un puente entre los gustos de los consumidores y la búsqueda del beneficio, todo ello bajo la palabra "arte". Esto no es arte según Pevsner quería que fuera. Como corolario, su definición del modernismo como el "estilo actual" se confronta a una pregunta simple. En los años treinta, ¿era ese el estilo o lo era el de los automóviles?

El diseño en las empresas industriales de automóviles de los años veinte y treinta sirve de antídoto a la ortodoxia de Pevsner y muestra las limitaciones de su narrativa. En esa época, las ventas de automóviles ford dejaron de aumentar y la competencia creciente de General Motors en el mercado estadounidense fue un hecho. Los problemas con el Ford-T eran problemas sociales de gusto. Tenía mala reputación. La solución no radicaba en reestudiar los sistemas productivos ni lanzarse en estrategias de reducción de costes. Era otra cosa. Los consumidores estaban aburridos con el color negro del modelo $T$ y querían un cambio.

¿Quién tenía los conocimientos y medios para elegir colores y estilos? Los diseñadores industriales emergen para darles a los automóviles lo que querían los consumidores, lo que calzaba con sus gustos e individualidades. El papel de los diseñadores que trabajaban para la industria automotriz pegó un gran salto con las exposiciones enormes que trataron de dar vuelta los efectos negativos de la Gran Depresión. Como hemos visto gracias a la obra fundamental del historiador Roland Marchand, en el trabajo de Walter Dormin Teague para la Ford Exhibit de 1934 y en el de Norman Bel Geddes' GM Futurama 1939-40 New York World's Fair Show, el diseño medió entre el capitalismo y las preferencias, entre un sistema económico y los gustos individuales. 
El papel valioso de los consultores en diseño y su contribución al diseño como práctica es cercano al trabajo de los diseñadores industriales contemporáneos porque estaban más inmersos en la producción industrial que los exquisitos diseñadores modernistas. Los objetos como los automóviles y trenes era tan temas de diseño como una lámpara o una silla. Tales objetos producidos a gran escala estaban fuera del modernismo ortodoxo que permanecía concentrado en objetos pertenecientes a la tradición de artes y oficios y a la de las artes decorativas. Como señaló Victor Margolin en relación con Moholy Nagy, esta fue la actitud típica hacia la in dustria que proviene de "la visión europea vanguardista que considera que el diseñador controla el producto".v Pevsner sufrió el mismo estigma incluso acentuado por sus pretensiones artísticas.

El fantasma es siempre el mismo. Es que los productos industriales puedan permanecer aparte del arte $y$ cercanos a la economía capitalista. Si son producidos por Deutscher Werbund, "eran producidos en una fábrica mediante maquinarias $y$ sus formas claramente lo expresan, su valor estético no se afecta en nada". Algunos años después, en una conferencia en x949, George Nelson movió los efectos de la industrialización a un nivel más democrático, "porque un segmento creciente de la población está finalmente comenzando a darse cuenta que un producto hecho por una máquina puede lucir como un producto hecho por una máquina y aún ser bello". Este segmento está alejado de los sujetos de Pevsner. Para el modernismo ellos fueron abstracciones puras que calzaban en un discurso seudo utópico, cuyo esquema era primero borrar la contingencia histórica para luego proclamar grandes ideales, y cuyo heroísmo fue cantado por Pevsner en clave de arte con un coro capitalista. 


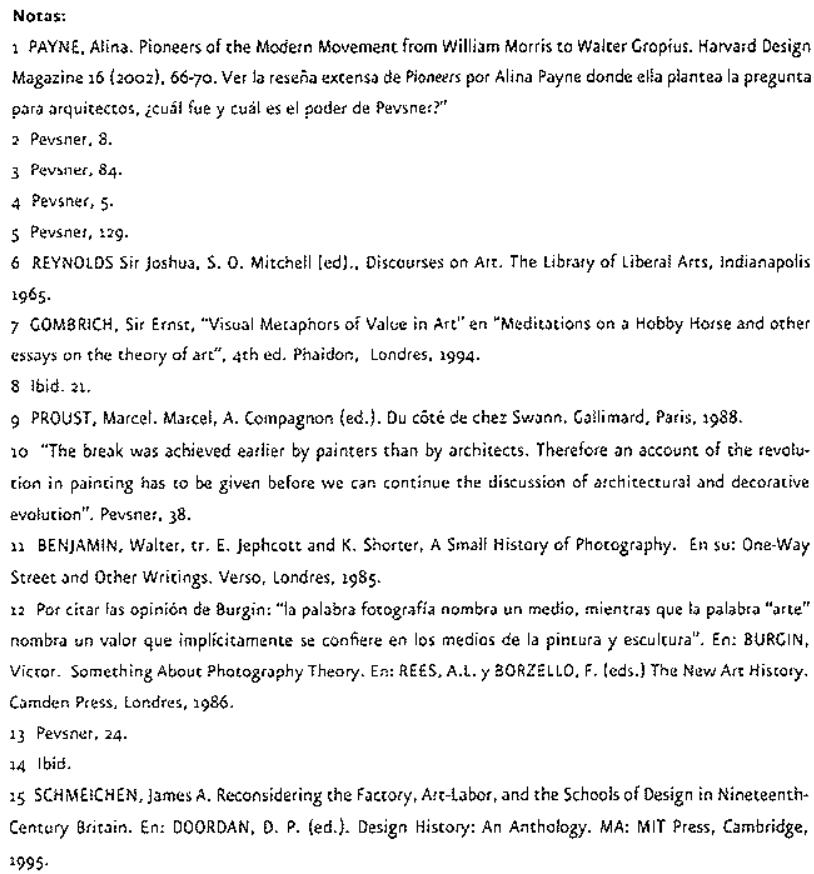
2995.

16 RYKWERT, Josepti. Reseña de Quentin Bell's The Schools of Design. The British Journal of Aesthetics $4(3) \cdot 1964$.

17 SAMUEL, Raphasel, Mechanization and Hand Labour in Industrializing Britain. En: BERLANSTEIN, Leonard R. (ed.). The tndustrial Revolution and Woik in Nineteenth Century Europe. Rourledge, Londres, 2992.

18 Estos tiacos apurecen en SHAW. William H. Finished Commodities Since 1879 fOccasional Paper $\mathrm{N}^{\circ} 3$ ]. Nationas Bureasu of Economic Research, Nueva York, 194:

29 BANHAM, Reyner. Theory and Design in the Firse Machine Age. $z^{*}$ ed. Praeger, Nueva York, 1967.

zo MARCHAND, Roland. Customer Research as Publit Relacions. General Motors in the 1930s. En: STRASSER, S., COVERN, C...M. y jUOT, M. (eds.). Getting and Spenting. European and American Societies in the Iwentieth Cencury. Cambridge University Press, Cambritge, 1998 .

21 Según Roland Maschand, las encuestas "colocaron a la investigación del cliente como la tomponente crucial del feedback dentro de una cadena que se vinculabo el Departamenco de ingenieria de ta empresa con Producción y luego con ventos, el vendedor, el consumidor, y-mediante investigación del cliente de vuelta nuevamente a ingenieria". Marchand, op.cit. 93 .

22 KRIPPENDORF, Kiaus. On the Essential Contexts of Artifacts or on the Proposition that 'Design' Is Making Sense (of Things). En: MARCOLIN, V. y BUCHANAN, R. (eds.). The Idea of Design. MIT Press, Cambridge, MA, : 998 .

23 Citado en Roland Marchand, op.cic. 95

24 Aunque el término "otro concreto" fue acuñado por Seyla Benhìbid en el contexto de la filosofía moral conternporánea y de la Teorís Crizica, si hizo perzinente en ia teoria y critica del diseño en DitNOT, Clive. The Gift. En: MARCOLIN. V. y BUCHANAN. R. (eds.). The. op.cit., 244-155. Para el "otro concreto", de Barhabid vėase "The Generalized and the Concrete Other. The Kohtberg-Gilligan Concroversy and Maral Theory" Praxis International $s:(4)(1986)$ 402-424; reimpreso en BENHABIB, Seyla y CORNEL1, Drucilla. (ed.). Feminism As Critique: Essoys on the Politics of Gender in Later-Capitalisc Societies. University of Minnesocra Press, Minneapoíis, 2987.

25 DOUCLAS, Mary. Thoughe Styles: Critical Essays On Cood Taste. Yhousand Oaks and Sage, Londriks y Niteva Deli, 1996. 
26 DOWGLAS, Mary e ISHERWOOD, Baron, The Wortd of Goods. Towards and Anthropology of Consumption. Routledge, Londres, 1996.

z) Benjamin, op.cit.

28 GO1DTHWATE, Richard A. The Building of Renaissance Florence. An Economic and Social History. The John Hopkins University Press, Baltimore y Londres, 2992.

29 MARCHANO. Roland. The Designers go to the Fair, i: Walter Dorwin Teague and the Professionalization of Corporate Industrial Exhibits, 2933-3940. En: DOORDAN, D. P. fed.). op.cit.

30 CARTMAN, David. "Harley Earl and the Art and Colo: Sertion: The Birth of Styling at Ceneral Motors" en D. P. Doordan ed. op.cit., 222-144.

31 MARCHAND, Roland. Customer Reseatch as Pubitic Relations. General Motors in the 1930s. op. cit. (note 22): The Designers go ro the Fais, I: Waiter Dorwin Teague and the Professionalization of Corporate Indistrial Exhibits, 1933-1940. op.cit. (note 30l: The Designers go to the Fair. II: Norman Bel Geddes. The General Motors "Futurama", and the Visit to the Factory Transformed. En: DOORDAN. D. P. Led.). Op.cit., xO3-221; MARCHAND, Roland. Advertising the American Dream: Making Way fo: Modernity, 1920 . 1940. University of California Press, Berkeley, 1985; MARCHAND, Roland. Creating the Corporate 5out: The Rise of Public Relations and Corporate Imagery in American Big Business. University of California Press. Berkeley, 1998 .

32 MARCOLIN, Victor. The Struggle for Utopia: Essays on Rodchenko, !issitzky and woholy-Nagy 1917. 2946. The University of Chicago Press, Chicago y londres, 2997.

33 NELSON, George. Problems of Design. Whitney cibrary of Design, New York. 1965. 